\title{
CHARACTERIZATION AND APPLICATIONS OF SILVER SULPHIDE BASED MEMBRANE ELECTRODES
}

\author{
A. Rajbhandari (Nyachhyon)*, A.P. Yadav*, K.Manandhar* and R.R. Pradhananga* \\ *Central Department of chemistry, Tribhuvan University, Kirtipur, Kathmandu, Nepal.
}

\begin{abstract}
The polycrystalline materials obtained by co-precipitation of silver sulphide and appropriate silver halide are used to prepare silver sulphide based membrane electrodes selective to the silver, chloride, bromide, iodide, and sulphide ions. The powder materials are characterized by x-ray diffraction, SEM equipped with EDAX. These membrane electrodes are found to give Nernstian response with the appropriate ions in the concentration range from $1 \times 10^{-1}$ to $1 \times 10^{-5} \mathrm{M}$. The performance of these home made electrodes is at par with the commercial electrodes. The electrodes have been successfully used for the quantitative determination of chloride, bromide iodide, silver, and sulphide ions and also for the determination of thiamine in pharmaceutical preparations. For developing countries like Nepal, who can not afford to procure high cost commercial ion selective electrodes, these home made ion selective electrodes are especially appealing since the electrode can be fabricated with ease in low cost and the electrode is well behaved and sufficiently accurate for the analysis with ion selective electrodes.
\end{abstract}

Key words: Ion selective electrode; Home made ion selective electrode; Silver sulphide; Thiamine; Vitamin B1.

\section{INTRODUCTION:}

After the advent of europium doped lanthanum fluoride single crystal ion selective electrode (ISE) in 1966, analysis with ion selective electrodes took a giant leap. Many ISE have been commercially available and method of analysis with ISE has been adopted as a standard method for the analysis of water and waste water, pharmaceutical preparations, environmental studies etc. [1-3]. Silver sulphide membrane electrode is one of the earliest ISE that have been well characterized and used [4]. The silver and sulphide ion electrodes are commercially available and can also be fabricated in the laboratory0[5-8].The commercial electrodes being quite expensive to the most of the teaching laboratory are not affordable for instructional use to students of developing countries which may deprive them from using such a powerful electro-analytical technique. Considering this fact in mind, we in our laboratory are developing and using silver sulphide base ion selective electrodes for educational purpose since several years [6]. The techniques of fabrication of all solid state silver sulphide electrodes and their uses in the direct potentiometric titration of halides and sulphide ions are described in our previous papers [4-8]. In the present paper, we have reported the characterization of composite polycrystalline materials used for fabrication of ISE by x-ray diffraction and SEM techniques. The selectivity of such composite electrodes for chloride, bromide, iodide, sulphide and silver ions and their applications for the assay of thiamine (vitamin $\mathrm{B}_{1}$ ) in pharmaceutical preparation are discussed.

\section{EXPERIMENTAL}

\section{Reagents}

All reagents were of analytical grade. Silver nitrate and thiamine hydrochloride were purchased from Sigma Aldrich. Sodium sulphide used was LR grade (minimum assay 52\%, SD’s). Commercial tablets containing vitamin $\mathrm{B}_{1}$ were obtained from local drug store. The pure powders and pulverised tablets were dried at $60^{\circ} \mathrm{C}$ for 2 hours under vacuum. All aqueous solutions were prepared with distilled water.

\section{Silver sulphide based ion selective electrode preparation}

Polycrystalline silver sulphide material was prepared by adding requisite amount of silver nitrate solution to sodium sulphide solution. The composite material was prepared by coprecipitation of silver halide and silver sulphide by adding appropriate amount of silver nitrate solution to the mixture of sodium sulphide and potassium halide in aqueous solutions. All solid state ISE membrane electrodes were fabricated from these materials, the details of which are given elsewhere [6]

\section{Instrumentation}

X-ray diffraction (Rigaku RINT 2500 HLR, Japan) and scanning electron microscope (SEM) equipped with EDAX (KEYENCE REAL 3D System, VE-series, Japan) were used to characterise the electrode material. Potentials were measured by using OSAW- digital potentiometer (India) relative to a silver/silver chloride (sat.) reference electrode. The potentio- 
metric measurements were made with the following electrochemical cell Ag\AgCl $\backslash \mathrm{KCl}$ (sat.) $\backslash \backslash$ sample solution $\backslash \mathrm{Ag}_{2} \mathrm{~S}$-AsX $\backslash \mathrm{Ag}$.

Determination of thiamine hydrochloride in Vitamin $B_{1}$ Tablet

Vitamin $B_{1}$ tablets were pulverised to fine powder and vacuum dried. Then the required amount of powder was dissolved in minimum amount (about $20 \mathrm{~mL}$ ) of water. The solution thus obtained was filtered into a $100 \mathrm{ml}$ volumetric flask and made up to the mark with distilled water. Requisite volume of the sample solution containing about $50 \mathrm{mg}$ of thiamine was transferred into a beaker, $10 \mathrm{~mL}$ of distilled water was added and titrated with $0.01 \mathrm{M}$ silver nitrate solution using silver sulphide membrane electrode. The end point of the titration was determined potentiometrically using Gran's plot [10-11]. The titration was also carried out in presence of $10 \mathrm{~mL}$ of $1 \mathrm{M} \mathrm{NaOH}$ solution.

\section{RESULTS AND DISCUSSION}

\section{Characterization of electrode material}

XRD pattern of laboratory prepared silver sulphide powder is shown in figure 1. In the figure, sharp diffraction peaks of crystalline silver sulphide indicating no detectable peaks for impurities in silver sulphide powder are observed. Diffraction pattern showed dominant peaks for $\operatorname{Ag}_{2} \mathrm{~S} 2$ theta at $26.189^{\circ}(111), 29.063^{\circ}(012), 31.820^{\circ}(120), 33.666^{\circ}(121)$, $34.743^{\circ}(112), 36.806^{\circ}(022), 37.6^{\circ}(200), 40.798^{\circ}(031), 43.47^{\circ}(130)$, $46.28^{\circ}(202)$ and $53.21^{\circ}(004)$ showing the polycrystalline nature of the silver sulphide powder and presence of any trace of Ag. Figure 2(a) is the scanning electron microscopic (SEM) picture of silver sulphide showing the surface morphology of silver sulphide powder and surface characteristic of silver sulphide. EDAX result was also obtained for further confirmation of the composition of silver sulphide. EDAX analysis result clearly shows the presence of Ag and S elements in atomic weight percentage as given in table (1)

Table 1: Results of elemental analysis by EDAX

\begin{tabular}{|c|c|}
\hline Element & Atomic weight \% \\
\hline $\mathrm{Ag} \mathrm{L}$ & 70.7 \\
\hline S K & 29.3 \\
\hline
\end{tabular}

Figures 2(b) and 2(c) are the EPMA image of silver sulphide showing the mapping images of silver and sulphur respectively.

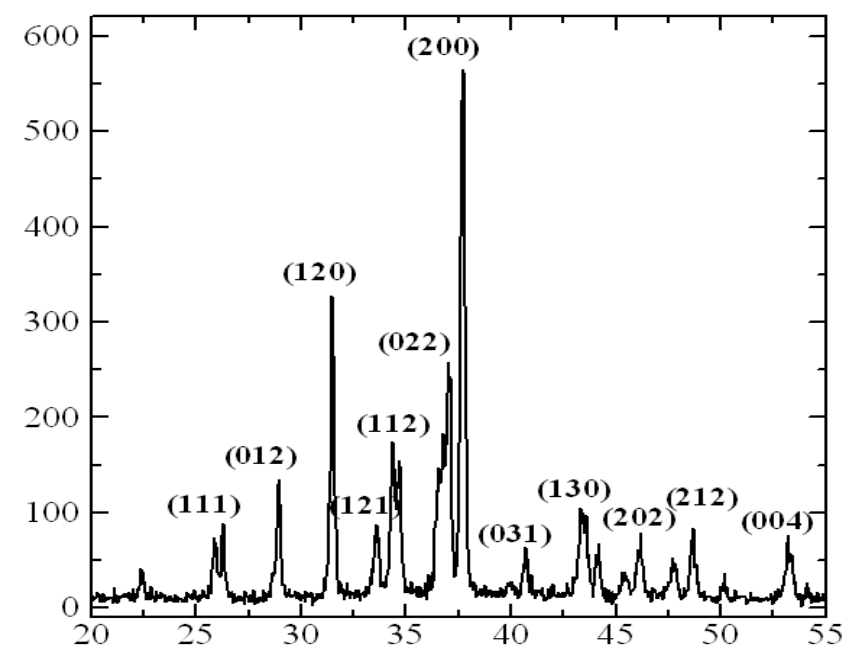

Fig. 1: XRD pattern of siver sulphide sintered at $110^{\circ} \mathrm{C}$
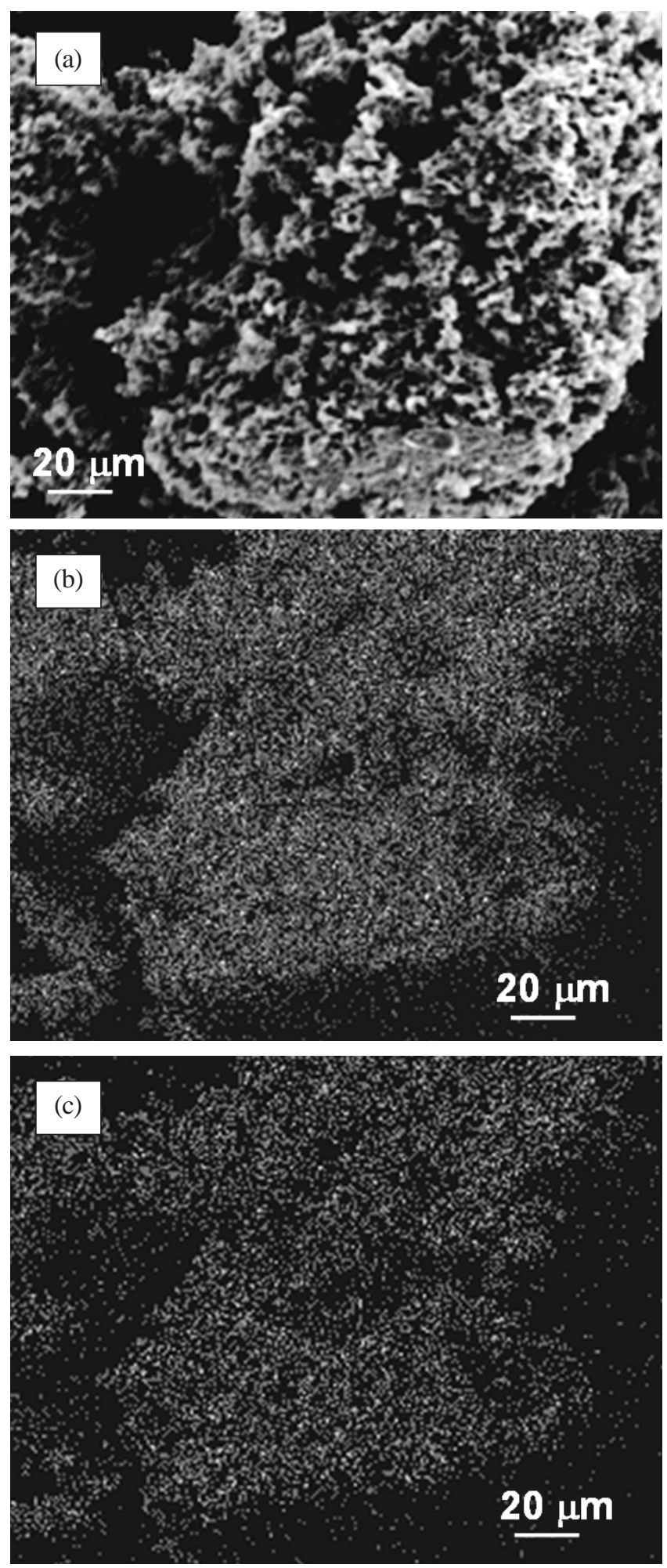

Fig. 2 (a) Scanning Electron Micrograph of $\mathrm{Ag}_{2} \mathrm{~S}$ (b) EPMA image of silver in silver sulphide sample (c) EPMA image of sulphur in silver sulphide sample

\section{$1.000 \times 10.0 \mu \mathrm{m}$ WD 11 .}

XRD patterns of laboratory prepared composite mixture of silver sulphide-silver iodide; silver sulphide-silver bromide and silver sulphide-silver chloride are shown in figures 3, 4 and 5 respectively. In these figures, one can see the sharp diffraction peaks of crystalline substances indicating no detectable peaks for impurities. 


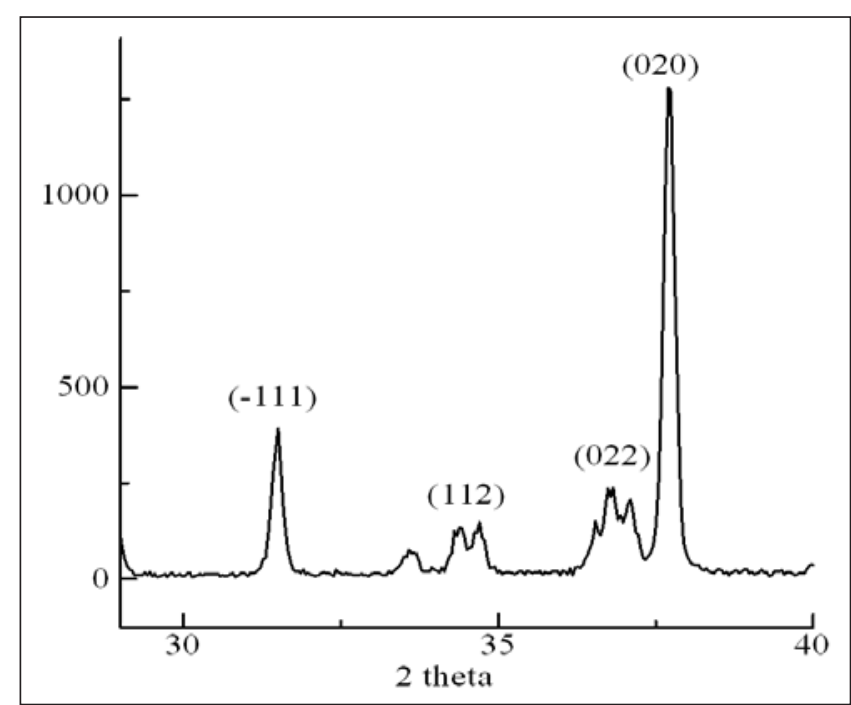

Fig. 3: XRD Pattern of $\mathrm{Ag}_{2} \mathrm{~S}-\mathrm{AgI}$

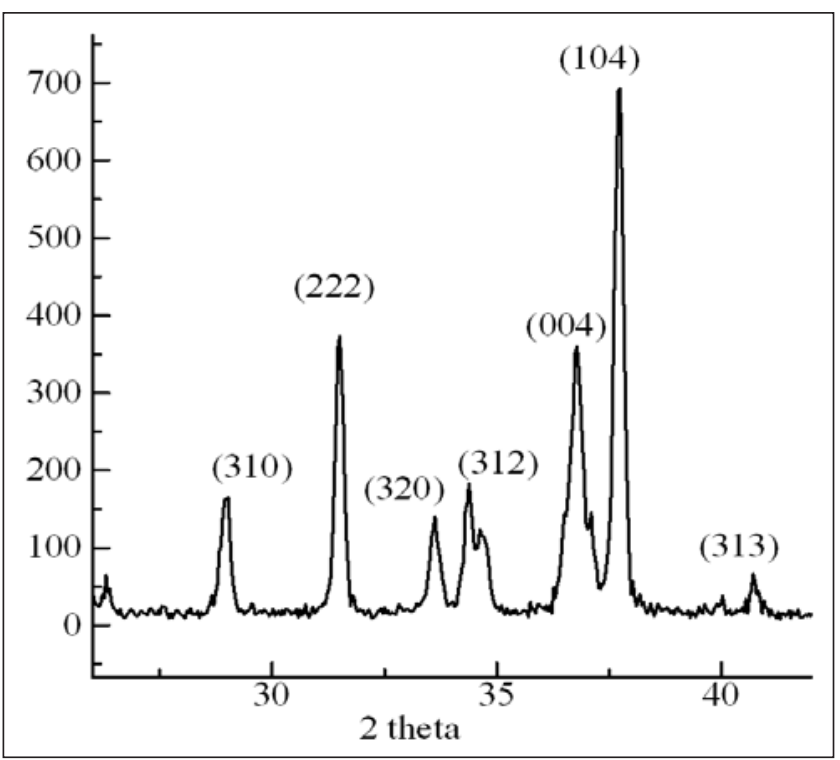

Fig. 4: XRD pattern of $\mathrm{Ag}_{2} \mathrm{~S}-\mathrm{AgBr}$

\subsection{Electrochemical characterization of electrodes}

Electrodes are electrochemically characterized for direct potentiometric determination of $\mathrm{Ag}^{+}, \mathrm{Cl}^{-}, \mathrm{Br}^{-}, \mathrm{I}^{-}$and $\mathrm{S}^{-}$ions. The electrodes showed Nernstian response in the concentration range of $1 \times 10^{-5}$ to $1 \times 10^{-1}$ in the ionic strength of $0.1 \mathrm{M}$. The results are tabulated in table 2 . The high values of coefficient of determinant indicate that the electrode response is sufficiently accurate for quantitative estimation of respective ion by direct potentiometry provided there are no interfering ions.

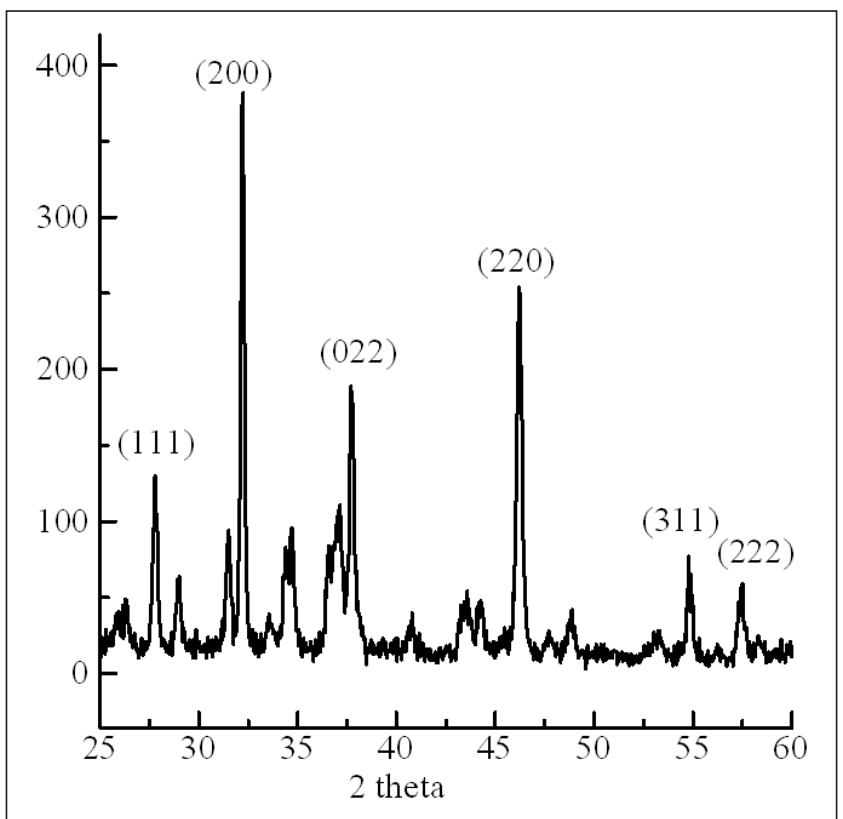

Fig. 5: XRD pattern of $\mathrm{Ag}_{2} \mathrm{~S}-\mathrm{AgCl}$

The effect of interfering ions is generally expressed in terms of potentiometric selectivity coefficients, $\mathrm{K}_{\mathrm{A}, \mathrm{B}}^{\mathrm{pot}}$ which are expressed according to Nickolsky - Eisenmann equation (1)

$\mathrm{E}=\mathrm{E}_{0}+\left(\mathrm{RT} / \mathrm{n}_{\mathrm{A}} \mathrm{F}\right) \ln \left(\mathrm{a}_{\mathrm{A}}+\sum \mathrm{K}^{\mathrm{pot}}{ }_{\mathrm{A}, \mathrm{B}}\left(\mathrm{a}_{\mathrm{B}}\right)^{\mathrm{n}}{ }_{\mathrm{A}} /{ }_{\mathrm{B}}{ }^{\mathrm{n}}\right)$

Where $a_{A}$ and $a_{B}$ are the activities of main and interfering ions having charges $n_{A}$ and $n_{B}$ respectively, $E_{0}$ is standard potential of the electrode and $K_{A, B}^{\text {pot }}$ is the selectivity coefficient which describes the relative sensitivity of determinant ion. The potentiometric selectivity co-efficient are determined by mixed solution method and the results are given in table 3 .

For most of the ions studied, the $\mathrm{pK}_{\mathrm{A}, \mathrm{B}}$ values of interfering ions are greater than 1 and positive indicating that interference by these ions are not adverse and even in presence of these interfering ions the concentration of the analyte can be determined with sufficient accuracy, with error less than a few percent. Only Iion interfere in the determination of bromide by BrISE, and I and Brions interfere adversely in the determination of chloride by Cl-ISE which is expected since solubility product of silver Iodide is less than that of silver bromide and similarly solubility product of silver chloride is less than that of silver bromide and silver iodide.

\subsection{Analysis of vitamin $B_{1}$ in pharmaceutical preparation}

The thiamine in crude material and pharmaceutical preparations can be determined by titrating the free chloride with

Table 2: Different constants of ion selective electrodes

\begin{tabular}{|l|c|c|c|c|c|}
\hline \multicolumn{1}{|c|}{ Electrode } & Determinant ion & slope & Intercept & Linear range & Coefficient of determinant \\
\hline $\mathrm{Ag}_{2} \mathrm{~S}$ & $\mathrm{Ag}^{+}$ & 59.8 & 606 & $1 \times 10^{-1}-1 \times 10^{-5} \mathrm{M}$ & 0.9933 \\
\hline $\mathrm{Ag}_{2} \mathrm{~S}-\mathrm{AgCl}$ & $\mathrm{Cl}^{-}$ & 58.1 & 27 & $1 \times 10^{-1}-1 \times 10^{-5} \mathrm{M}$ & 0.9911 \\
\hline $\mathrm{Ag}_{2} \mathrm{~S}-\mathrm{AgBr}$ & $\mathrm{Br}^{-}$ & 57.2 & 175 & $1 \times 10^{-1}-1 \times 10^{-5} \mathrm{M}$ & 0.9803 \\
\hline $\mathrm{Ag}_{2} \mathrm{~S}-\mathrm{AgI}$ & $\mathrm{I}^{-}$ & 57.5 & -339 & $1 \times 10^{-1}-1 \times 10^{-5} \mathrm{M}$ & 0.9865 \\
\hline $\mathrm{Ag}_{2} \mathrm{~S}$ & $\mathrm{~S}^{-}$ & 30.0 & 911.5 & $1 \times 10^{-1}-1 \times 10^{-5} \mathrm{M}$ & 0.9961 \\
\hline
\end{tabular}


Table 3: Selectivity coefficients

\begin{tabular}{|l|c|c|c|}
\hline Electrode & Determinand ion & Interfering ion & $\mathbf{p K}_{\mathbf{A}, \mathbf{B}}$ \\
\hline \multirow{4}{*}{$\mathrm{Ag}_{2} \mathrm{~S}$} & \multirow{3}{*}{$\mathrm{Ag}^{+}$} & $\mathrm{Hg}^{+}$ & 3.2 \\
\cline { 3 - 4 } & & $\mathrm{Cr}^{+3}$ & 4.2 \\
\cline { 3 - 4 } & & $\mathrm{Pb}^{+2}$ & 4.3 \\
\cline { 3 - 4 } & & $\mathrm{Zn}^{+2}$ & 4.1 \\
\cline { 3 - 4 } $\mathrm{Ag}_{2} \mathrm{~S}-\mathrm{AgI}$ & \multirow{2}{*}{$\mathrm{I}^{-}$} & $\mathrm{Mg}^{+2}$ & 4.2 \\
\hline \multirow{2}{*}{$\mathrm{Ag}_{2} \mathrm{~S}-\mathrm{AgBr}$} & & $\mathrm{Cl}^{-}$ & 2.1 \\
\hline \multirow{2}{*}{$\mathrm{Ag}_{2} \mathrm{~S}-\mathrm{AgCl}$} & \multirow{2}{*}{$\mathrm{Br}^{-}$} & $\mathrm{Br}^{-}$ & 1.75 \\
\cline { 3 - 4 } & & $\mathrm{Cl}^{-}$ & -0.6 \\
\cline { 3 - 4 } & \multirow{2}{*}{$\mathrm{Cl}^{-}$} & $\mathrm{Br}^{-}$ & -1.09 \\
\cline { 3 - 4 } & & \multicolumn{2}{c}{-1.69} \\
\hline
\end{tabular}

silver nitrate using Chloride-ISE electrode. Thiamine hydrochloride is the hydrochloride of a thiozolium chloride derivative with two dissociable chloride ions per molecule of thiamine [12-13]. The potentiometric titration of $50 \mathrm{mg}$ of thiamine with $0.01 \mathrm{M}$ silver nitrate in neutral medium is shown in figure (6) curve (a). There is a clear potential break corresponding to the consumption of 2.0 mole of silver nitrate per mole of thiamine. The method is quite simple, sensitive and gives reproducible result in crude vitamin $B_{1}$. But the pharmaceutical preparation may contain chloride from other vitamin sources as well; in such case the method is neither applicable nor selective for determination of thiamine. However, even in the presence of hydrochlorides from other vitamins, thiamine in pharmaceutical preparation can still be determined by argentometric titration in highly alkaline medium at around $\mathrm{pH} \geq 11$.6. Under highly alkaline condition the thiozole ring of thiamine is known to open readily yielding thiol which can react with silver ion to give mercaptide as shown in reaction scheme 1 [14]. Furthermore, in presence of sodium hydroxide, silver ions do not react with free chloride but react with thiols only [13]

\section{Reaction Scheme 1}

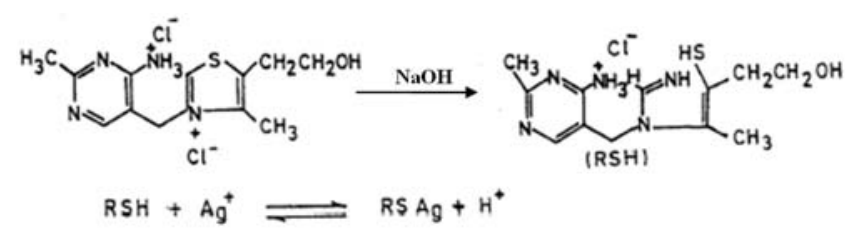

Figure 8 curve b shows the potentiometric titration curve of pure thiamine with silver nitrate in highly alkaline medium $\left(\geq 5 \times 10^{-1} \mathrm{M} \mathrm{NaOH}\right)$. A clear inflation points is observed in the curve at the consumption of 0.76 mole of silver ion per mole of thiamine. The end point is found to be not affected by addition of chlorides prior to the titration of thiamine with $\mathrm{AgNO}_{3}$ in alkaline medium. Thus the end point of argentometric titration in alkaline medium can be used to determine the thiamine not only in pure powders but also in pharmaceutical preparation. Other vitamin and free chlorides do not interfere. Since the reaction of silver ion with thiamine in alkaline condition is not exactly stoichiometric hence silver nitrate solution need to be standardized with the help of authentic sample of thiamine. The potentiometric titration in highly alkaline medium with standard silver nitrate solution has been used to determine the thiamine in the vitamin tablets, the results obtained are in agreement with the amount of thiamine determined by HPLC technique within experimental limit of error and with the manufacturer's specification. This indicates the validity of the present method of determination of thiamine of pharmaceutical preparation. The present method is very simple, inexpensive, and sufficiently accurate. It can be readily used to determine thiamine in pharmaceutical preparation.

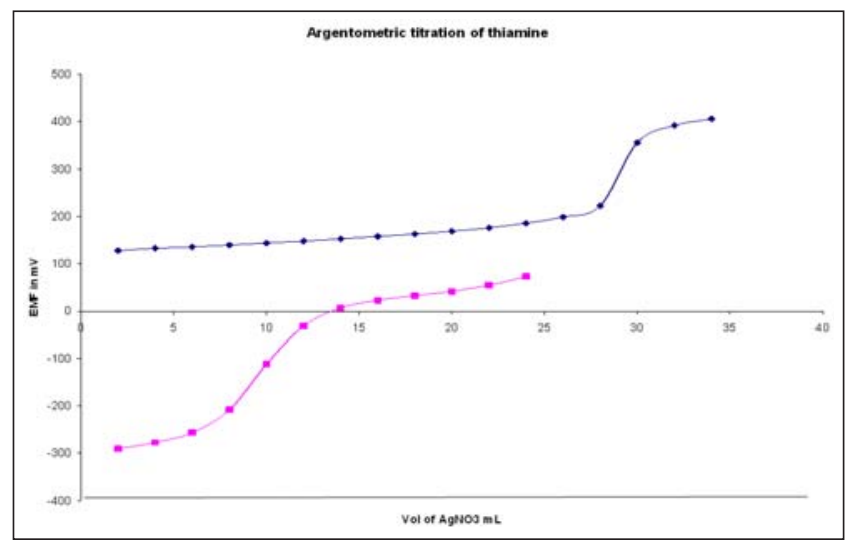

Figure 6: Potentiometric curves for the titration of $50 \mathrm{mg}$ of thiamine with silver nitrate solution in (a) neutral medium (b) in highly alkaline medium using home made silver sulphide membrane as indicator electrode.

\section{CONCLUSION}

Effective Ion selective membrane electrode based on silver sulphide is possible to prepare by the co-precipitation of silver halide and silver sulphide composite mixture. The home made ion selective electrodes are useful to determine $\mathrm{Ag}^{+}, \mathrm{Cl}^{-}$ , $\mathrm{Br}^{-}, \mathrm{I}^{-}$and $\mathrm{S}^{--}$ions by direct potentiometry and thiamine in pure and crude form including pharmaceutical preparation can be determine by argentometric titration in presence of sodium hydroxide using home made silver sulphide membrane as an indicator electrode. Determination of thiamine by such silver sulphide membrane electrode is simple, inexpensive and sufficiently accurate.

\section{ACKNOWLEDGEMENTS}

One of the authors (AR) is thankful to Tribhuvan University for granting study leave and National Academy of Science and Technology (NAST) for providing PhD Scholarship to carry out this work. The authors gratefully acknowledge Tsuru-Nishikata laboratory, Tokyo Institute of Technology, Tokyo, for providing facilities to record XRD and SEM images of the material. We are also thankful to the Head, Central Department of Chemistry for providing all the necessary facilities to carry out this work.

\section{REFERENCES}

1. Clesceri, L.S, Greenberg, A.E, and Eaton, A.D. 1998. Standard Methods for the Examination of Water and Wastewater, $20^{\text {th }}$ edition, APHA, AWWA,WEF Washington DC 20005-2605.

2. ASTM. 1992. Annual Book of ASTM Standards, Water and Environmental Technology, American Society for Testing Materials.

3. EPA. 1983. Methods for Chemical Analysis of Water and Wastes. Environmental Protection Agency (EPA), Environmental Monitoring Systems Laboratory, EPA-600/4-79-020. 
4. Hseu,T. and Rechnitz, G.A, 1968. Analytical study of a sulphide ion-selective membrane electrodes in alkaline solution, Analytical chemistry. 40: 1054-1060.

5. Pradhananga, R.R.and Rajbhandari (Nyachhyon), A. 2008. Low cost electrochemical sensors for silver, chloride, bromide and iodide ions, Scientific World. 6: 33-36.

6. Pradhanang, R.R. and Shrestha, L.K. 2008. Home made ion selective electrodes for education, Transactions of Materials Royal Society of Japan. 33: 345-349.

7. Yadav, A.P. and Pradhananga, R.R. 1996. Preparation and characterization of silve sulphide/silver iodide ion selective electrodes for the determination of $\mathrm{I}, \mathrm{S}^{-}$and $\mathrm{Ag}^{+}$ions. J. Nep. Chem. Soc. 15: 19-26.

8. Yadav, A.P. and Pradhananga, R.R. 1994. Analytical study of polycrystalline thick film $\mathrm{Ag}_{2} \mathrm{~S}$ based ion selective electrode. II national conference on Science \& Tech, RONAST, Abs No Chem. 8: Kathmandu, Nepal.

9. Pradhananga, R.R. and Shrestha, L.K. 2001. Application of Ag-ion selective electrode for the determination of solubility products of different sparingly soluble silver salts. Anal. Science (Japan). 17 (Supplement): 395-a396.

10. Gran, G. 1952. Anlyst (London). 77: 661.

11. Giri, B. and Pradhananga, R.R. 2005. Location of end point in potentiometric argentometric titration using Gran plot and titration error, J. of Inst. Sci \& Tech. 14: 108-115.

12. Mailer, G.D. and Metzler, D.E. 1957. Structures of Thiamine in Basic Solution. J. Am. Chem. Soc. 79: 4386.

13. Hassam, S.S. and Eman, E. 1989. Selective determination of thiamine0(vitaminB1) in pharmaceutical preparations by direct potentiometric argentometric titration with use of silver-silver sulphide ion selective electrode. Talanta. 36: 1011-1015.

14. Srividya, K. and Balasubramanian, N. 1997. Indirect spectrophotometric determination of thiamine in pharmaceutical preparations. Chem. Phar. Bull. 45: 2100-2103. 